\title{
A Fuzzy Rule-Based Approach to Design Game Rules in a Mission Planning and Evaluation System
}

\author{
D. Vijay Rao and Jasleen Kaur \\ Institute for Systems Studies and Analyses \\ Defence Research and Development Organisation, \\ Metcalfe House, Delhi 110054, India \\ doctor.rao.cs@gmail.com
}

\begin{abstract}
Simulations and wargames offer powerful representations to model the mechanics and psychology of military operations that are inherently complex. They offer mechanisms to predict and assess the effectiveness of the mission plans and operations in achieving the military objectives. In this paper, we present a new approach to design the games rules of wargames using fuzzy rule bases, for quantitatively evaluating the effectiveness of air tasking missions. We determine the comparative damage relative to intended damage for a target, taking into account the effects of operational characteristics to compute possibilistic damage to the target as opposed to the probability of damage to the target. The cookie-cutter method to compute the damage is modeled as a fuzzy variable. Effectiveness of the mission is obtained by comparing the damage to targets with the cost and significance of the target in meeting the mission objectives. Damage assessment computation to targets using fuzzy rule bases gave more realistic results when used in field training and deployment of the system.
\end{abstract}

Keywords: Military simulation, Mission effectiveness, Rule-based systems, Damage Assessment Modeling, Fuzzy logic.

\section{Introduction}

Simulation has been applied extensively and successfully to a wide range of military problems, including wargaming, acquisition, logistics, and communications. It has been used as a decision support tool to evaluate how a battle force should be constituted, how to plan the force strength and structures, how it might be deployed, and how the weapon systems should be acquired and maintained. Wargames constitute an important class of applications that have proved to be an important tool for military system analyses and an inexpensive alternate to live training exercises. However, modeling the complexity and battle dynamics of the real world, assessing and predicting the outcomes of missions plans quantitatively and accurately is a very difficult endeavor [1],[3]. Air Wargame Simulation System (AWGSS) is a wargaming software that has been developed for planning and evaluating air tasking operations (missions) [3]. Given a military objective, the air component commander plans missions, minimizes the risk while targeting, chooses appropriate weapons for 
targeting while ensuring the intended damage is caused to the target. This is done considering the enemy forces' deployment, weather and terrain encountered en-route and suitability of aircraft, weapons for achieving the objectives. Traditionally, the occurrence of various events has been represented using probability distributions, a set of game rules that represent various situations and classical logic to compute the damage assessment. Damage assessments for targets were implemented using crisp cookie-cutter function that gives the probability of damage of a target. These methods are found to be inadequate in the present war scenario, to generate a realistic assessment of the mission plans due to uncertainty and vagueness of the factors considered. In this paper, we present a novel approach to design the games rules of wargames using fuzzy rule bases, for quantitatively evaluating the effectiveness of air tasking missions.

\section{Fuzzy Rule-Based Representation of Game Rules}

Traditional approaches to wargame simulations use classical logic for damage assessment. Classical two-valued logic system, crisp set theory and crisp probability on which the damage assessment is based, are inadequate and insufficient for dealing with real-life war scenario that involves complexity and different sources of uncertainty. Damage assessment for a target done using cookie-cutter function gives the probability of damage of a target. Crisp cookie-cutter function states that a target is damaged inside a circle of specified radius $r$, and no damage occurs outside it [3].

$$
d(x, y)=\left\{\begin{array}{l}
1, x^{2}+y^{2} \leq r^{2} \\
0, \text { otherwise }
\end{array}\right.
$$

where, $d(x, y)$ is the damage function of the point target by a weapon whose point of impact is $(x, y)$. The target is assumed to be completely damaged within the circle of radius $r$ and no damage occurs outside $r$. The notion of probability stems from, and depends on, the idea of repeated trials. Under identical and repeatable laboratory conditions conducted on simple models, this probabilistic notion readily applies; but, in real-world systems, experiments are rarely identical and repeatable. Therefore, for the subjective assessment of complex military systems, probability has its limitations. Game rules in conventional mission processing are limited and simplistic, taking into account limited number of parameters and based on statistical distributions. They do not take into consideration, effects of weather conditions, operational environment, target attributes, significance attached with the target, visibility of target at time of target acquisition, and effects of terrain while assessing damage. Variables such as these play a vital role in mission planning, mission processing and damage assessment. Different commanders deciding on the result of a planned mission are usually subjective based on their experiences. In order to overcome the limitations of statistically steady state results for game rules, we propose a fuzzy rule based approach for the design of the game rules. What is gained through fuzzification is greater generality, higher expressive power, an enhanced ability to model real-life problems, a methodology for exploiting the tolerance for imprecision and which 
serves to achieve tractability and robustness [2],[4]. Fuzzy Logic is the logic behind approximate reasoning instead of exact reasoning. As knowledge acquisition in wargames design and development is obtained from pilots and defence analysts, it is usually true that facts and rules are neither totally certain nor totally consistent due to the varied experience sets of the pilots. This leads to the reasoning processes used by experts in certain situations as approximate. In this paper, the theory of fuzzy sets is used to help assess uncertain information derived from this approximate reasoning process. Features of Fuzzy Logic that give it a realistic implementation than classical logic are:-

1. Fuzzy Logic offers far greater resources for managing complexity and controlling computational cost. More complex the problem involved, the greater the superiority of fuzzy methods.

2. Fuzzy Logic has greater expressive power. It has the capability to capture and deal with meanings of sentences expressed in natural language. This capability allows to deal in mathematical terms with problems that require the use of natural language.

3. Fuzzy Logic has capability to capture human common-sense reasoning, decision making and other aspects of human cognition.

4. Data which are based on graded distinctions among states of relevant variables are usually called fuzzy data. When fuzzy data are processed, their intrinsic uncertainties are processed as well, and the results obtained are more meaningful, than their counterparts obtained by processing the usual crisp data.

In any given language the values of a linguistic variable are words, phrases, or sentences. For example, structural damage can be considered as a linguistic variable with values such as "severely damaged," or "moderately damaged." These are meaningful classifications but not clearly defined. With the use of fuzzy sets, however, we can quantify such terminology and apply it in a meaningful way to help solve a complex problem. An evident advantage of the fuzzy set approach is the possibility of representing numeric and linguistic variables in a uniform way and of using a formalized calculus to manipulate these variables [3],[4].

\section{Identification of Factors for Damage Assessment}

The metric "comparative damage relative to intended damage" gives a measure of damage caused to the target relative to the damage that was intended to be caused, when the weapon was delivered. It uses various factors as its input variables such as Offset, Weapon Suitability, Weapon Delivery Mode, Target Identification factor and Terrain. Meetings with the pilots and analysts helped in identifying following parameters to be considered while assessing damage.

(1) Offset is the measure of deviation of actual point of impact from desired point of impact. It is calculated using actual altitude, actual vertical flight path angle, actual wind speed and observed altitude, observed vertical flight path angle, observed wind speed by the weapon system trajectory calculation module and the aircraft speed as the input variables. Offset is a measure of Altitude induced error, wind induced error, vertical flight path angle induced error. [3],[5],[6],[7]. 
(2) Weapon Suitability factor takes into account weapon characteristics, weapon's suitability in the operational conditions and weapon-target matching. Apart from the geo-political and threat environment factors such as weapon/target matching, affordability and maintainability are also considered. The weapon is chosen for attack considers parameters such as attack conditions, significance attached with the target versus cost of weapon, platform for weapon delivery, target-weapon match and collateral damage. Weapon Suitability factor is rated on the scale of 0 to 10 considering following factors:-

-Operational Environment and Weather Conditions: Operational environment and weather conditions play an important role in deciding the suitability of the weapon for a target. For instance, poor weather and conflict induced environmental conditions such as smoke from bombing etc. may degrade or block the IR, EO or laser targeting sensors required for delivery of guidance ordnance. LGBs cannot be used in poor weather where target illumination cannot be seen, or where it is not possible to get target designator near the target. However, poor visibility does not affect satellite guided bombs. Only comparatively inaccurately unguided bombs could be delivered in poor weather.

-Cost versus Target Significance: The expenditure incurred in using a weapon against a target should be justified taking into account significance attached with the target. For instance, there are high costs associated with the usage of guided munitions; they must not be neglected in cost-benefit analyses and the deliberation processes that are intrinsic to capital equipment purchases. The comparatively high cost of guided bombs and resulting smaller inventories is also an important factor in weapon suitability factor.

-Aircraft Compatibility: Compatibility of the aircraft for weapon delivery is an important factor. Weapons must be compatible for carriage and release with the combat aircraft types.

-Weapon-Target matching: Target size and target hardness are factors that need to be considered for deciding the suitability of a weapon against a target. For large targets, use of unguided ordnance is appropriate. LGB capable aircrafts could deliver penetrating LGBs. LGBs are particularly useful against hardened, reinforced, buried reinforced targets. The aim of matching weapons to targets is to achieve the desired level of damage for the least number of sorties while minimizing the risk to the weapons delivery platform. Weapons employed against certain targets such as ships must be inherently maneuverable so they can accommodate target velocity after launch.

-Collateral Damage: Although advances in weapon aiming systems have improved the accuracy of unguided air-delivered munitions, collateral damage cannot be discounted. PGMs must be employed against military objectives where there is a possibility of collateral damage to civilians or civilian objects.

(3) Weapon Delivery Mode is another factor considered for calculating damage. It takes into account aircraft for weapon delivery, weapon chosen and target characteristics. A value is assigned on the scale of 0 to 10 . Three basic delivery modes considered are Roll, Toss and Dive. Weapons can be either direct attack (freefall, accurate, or precision) or standoff. Direct attack weapons require an aircraft to maneuver to a release point. Stand-off weapons enhance an aircraft's survivability by 
allowing it to deliver ordnance at increased distance from the enemy's defenses. Planners and crews prefer launch-and-leave weapons to those requiring line of sight with the target. These tend to be much more expensive and fewer in number than other weapons.

(4) Target Identification factor: Rapid and certain target detection and identification are the dominant factors in the success of all air-to-ground attacks. The ability of tactical fighters to penetrate enemy defenses and to acquire and identify ground targets successfully is a keystone of success in a mission. Enemy defenses have necessitated higher speeds and higher altitudes. The employment of standoff weapons demands acquisition and identification of targets at even greater ranges. It has been observed that aerial observers respond to targets in a manner indicating that detection / identification represents a continuum rather than discrete phenomena. At one extreme the response is based on the ability to merely discriminate the existence of a military object among non-military objects (detection). At the other extreme the observer can describe the object in precise detail (identification). Factors considered for computing the Target Identification factor are target size, percent contrast, illumination, terrain, altitude and speed of the aircraft at time of target acquisition.

-Target Size: As target size increases, probability of correct target identification increases. It may vary from small to large tactical targets, including personnel, trucks, and tanks to big targets as bridges, runways and taxi-tracks.

-Contrast: Target/Ground Brightness Contrast is expressed as a percentage.

-Illumination: Detection performance increases as illumination increases. Effects of decreases in illumination occurring after sunset and before sunrise are very important and need to be considered.

-Terrain: Types of terrain have been defined in terms such as number of slope changes per unit area and average slope change. Four different terrain types have been defined--fairly smooth, moderately rough, rough, and very rough. As the roughness of terrain increases, percent terrain view decreases, and decrease in detection performance is observed.

-Altitude: The relationship between altitude and target detection/identification is normally one in which there is assumed to be an optimal altitude; above and below this optimum altitude, detection is reduced. As altitude increases, detection performance decreases. As altitude is increased beyond an optimal point, detection probability falls off rapidly.

Data on all these factors are collected from handbooks and experimental field trials and subjective decisions from experts and defense analysts (in questionnaire form) are collected and recorded. They are then represented as decision matrices and decision trees which form the basis to design the membership functions and rules. The rules are then executed in the mission processing module and defuzzified to obtain the damage to target. These results are then compared to the expected output and finetuned before storing in the rule base. A decision to include the new rule or not is provided to the commander. Missions and results of the missions are stored as a casebase for retrieval and reuse of missions plans in new situations. The following fuzzy linguistic variables used in the design of the game rules are as follows: 


\section{Terrain: 1- 100}

\{Fairly Smooth [0 -22]; Moderately Rough [14 - 49]; Rough [45-81];

Very Rough [75 - 100]\}.

Target Size (in feet):

\{Very small: 0 -100; Small: 70 - 190; Medium sized: 160 - 300;

Large: 270 - 400; Fairly Large: 360 - 500; Extremely Large: 450 - 900

\section{Damage: Offset (in meters):}

\{Very Less:[0-23]; Less:[16-36]; Medium: [34-57]; Large: [56-80];

Very Large [78-100]\}

\section{Weapon Target Match: [0 to 10]}

\{Poor: [0-3.6]; Average: [3.36-6.669]; Good: [6.73-14.2]\}

\section{Target Identification Factor: [0 -10]}

\{Very poorly identified: [0-1.19]; Poorly identified [0.96-2.43]; Average identification [2.34 - 5.61]; Good identification [5.43 - 7.55]; Excellent identification $[7.35-10]\}$

Relative Damage (Damage relative to intended damage): [0 - 100]

\{Mild: [0-18]; Moderate: [16-36]; Average: [34-57]; Severe: [56-80]; Fully Damaged: [78-96]\}

These fuzzy variables to calculate the target identification factor are depicted in the Mamdani FIS as shown in Fig. 1 and firing of the rules to compute the relative damage to the target are depicted in Fig. 2. Offset is calculated using Actual altitude, actual vertical flight path angle, actual wind speed and Observed altitude, observed altitude, observed vertical flight path angle, observed wind speed by the weapon system trajectory calculation module and the aircraft speed as the input variables (Table3). Offset is a measure of induced error, wind induced error, and vertical flight path angle induced error.

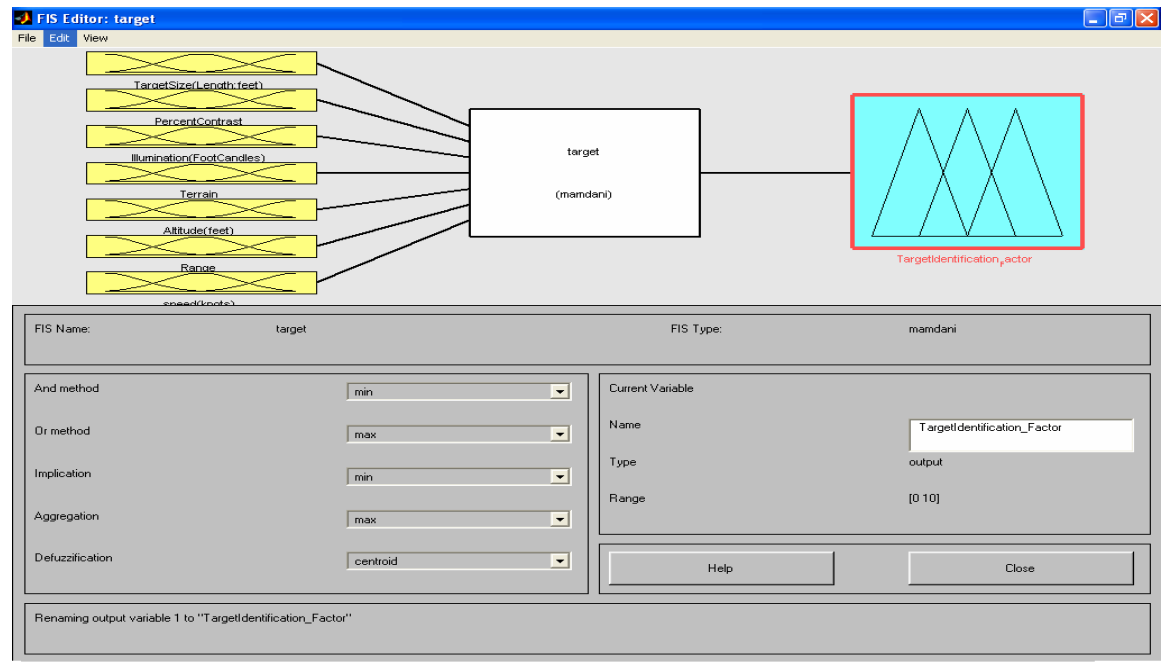

Fig. 1. Mamdami Fuzzy logic Inference System for computing Target Identification factor 


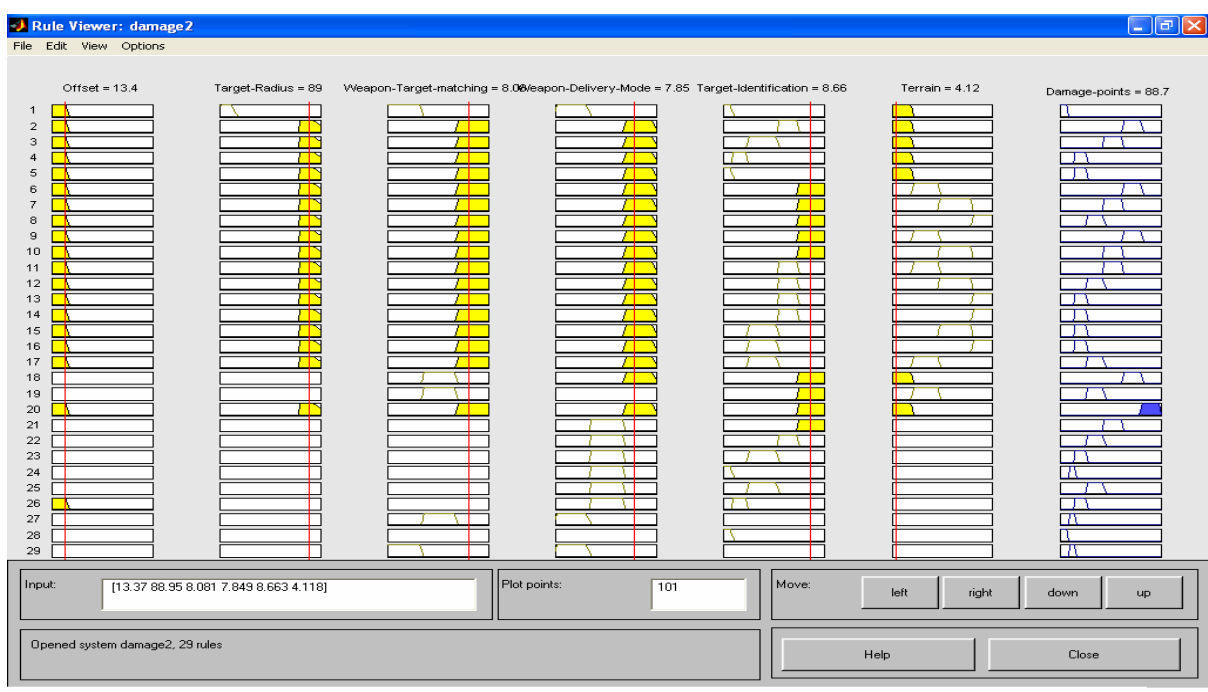

Fig. 2. Fuzzy Rules and their firing for the Mamdami FIS for finding Damage caused in relation to the intended damage

\section{Results}

Case Mission ID \# 001: Consider a large area-target of size of $550 \mathrm{ft}$ to be attacked, where the fuzzy variables target-ground contrast $80 \%$, the terrain, rated 8 , is fairly smooth, aircraft altitude is $900 \mathrm{ft}$, aircraft range is $5000 \mathrm{ft}$ is flying at 100 knots speed.

Table 1. Fuzzy Rules to determine the Target Identification factor

\begin{tabular}{|c|c|c|c|c|c|c|c|c|}
\hline MissionID & $\begin{array}{l}\text { Target } \\
\text { Size(ft) }\end{array}$ & $\begin{array}{l}\text { Target- } \\
\text { Ground } \\
\text { Contrast\% }\end{array}$ & $\begin{array}{l}\text { Illumination } \\
\text { (foot candles) }\end{array}$ & Terrain & $\begin{array}{l}\text { Aircraft } \\
\text { Altitude(feet) }\end{array}$ & $\begin{array}{l}\text { Aircraft } \\
\text { Range(feet) }\end{array}$ & $\begin{array}{l}\text { Aircraft } \\
\text { Speed } \\
\text { (knots) }\end{array}$ & $\begin{array}{l}\text { Target } \\
\text { Identify } \\
\text { Factor }\end{array}$ \\
\hline$\# 001$ & 550 & 80 & 40 & 8 & 900 & 5000 & 100 & 7.3295 \\
\hline$\# 002$ & 550 & 80 & 60 & 7 & 750 & 4000 & 80 & 8.0333 \\
\hline
\end{tabular}

Table 2. Fuzzy Rules to compute the Relative damage to target

\begin{tabular}{|c|c|c|c|c|c|c|}
\hline MissionID & $\begin{array}{l}\text { Offset } \\
\text { (meters) }\end{array}$ & $\begin{array}{c}\text { Target } \\
\text { Radius (km) }\end{array}$ & $\begin{array}{l}\text { Weapon-Target } \\
\text { Match }\end{array}$ & $\begin{array}{l}\text { Weapon } \\
\text { Delivery Mode }\end{array}$ & $\begin{array}{l}\text { Target Identify } \\
\text { Factor }\end{array}$ & $\begin{array}{l}\text { Relative } \\
\text { damage }\end{array}$ \\
\hline$\# 001$ & 29.027 & 0.0900 & 6 & 6 & 7.3295 & 28.9187 \\
\hline$\# 002$ & 6.0696 & 90 & 9 & 9 & 8.0333 & 88.7410 \\
\hline
\end{tabular}

The target identification factor for this target is seen as "good" with value 7.3295. In this mission, on firing the rules for inference, the offset from the desired point of impact is $29 \mathrm{~m}$, considered "less"(i.e. fairly accurate targeting); weapon-target match is 6 (average), "good" target identification factor 7.3295, the relative damage caused is 28.9187 which is a "moderate" damage to the target. 
Table 3. Fuzzy attributes to determine the offset of the weapon from the intended target

\begin{tabular}{|c|c|c|l|l|l|l|l|l|}
\hline $\begin{array}{c}\text { Mission } \\
\text { ID \# }\end{array}$ & $\begin{array}{c}\text { Apparent } \\
\text { Altitude(km) }\end{array}$ & $\begin{array}{l}\text { Apparent } \\
\text { Angle } \\
\text { (degrees) }\end{array}$ & $\begin{array}{l}\text { Apparent } \\
\text { Wind } \\
\text { vilocity } \\
(\mathrm{km} / \mathrm{hr})\end{array}$ & $\begin{array}{l}\text { Actual } \\
\text { Altitude(km) }\end{array}$ & $\begin{array}{l}\text { Actual } \\
\text { Angle(degrees) }\end{array}$ & $\begin{array}{l}\text { Wind } \\
\text { velocity } \\
\text { (km/hr) }\end{array}$ & $\begin{array}{l}\text { Aircraft } \\
\text { speed(km/hr) }\end{array}$ & $\begin{array}{l}\text { Offset } \\
(\text { meters) }\end{array}$ \\
\hline 001 & 1.64592 & -26.9 & - & 1.6764 & -26.9 & -25.236 & 829.8 & 29.0271 \\
\hline 002 & 1.65 & -25 & -28 & 1.65 & -25 & -30 & 830 & 6.0696 \\
\hline
\end{tabular}

Case Mission ID \# 002: We now consider another mission planned by the commander where a similar target is chosen with the fuzzy variables as shown in Tables 1 and 2 . While the offset has reduced to $6 \mathrm{~m}$, considered "very less" (i.e. very accurate targeting), choosing a different weapon system and delivery improved the weapontarget match to 9 ("good"), and mode of weapon delivery 9, the target identification factor also improved to 8.033 (considered "excellent"), and the relative damage caused is 88.7410 , which is a "substantial" damage to the target. (Tables 1,2). These attributes form the antecedents of the fuzzy rule and the consequent is shown in the last column of the tables. For all the missions that the pilots plan in the wargame exercises, these fuzzy game rules are used to infer the expected damage caused to the target. These missions form a part of a case-base which is used as part of the 'learning' by the system for future instructional use.

\section{Conclusions}

We present a novel approach using a fuzzy rule-based system to design the game rules in a mission planning and evaluation system. The conventional crisp cookie cutter function used to compute the probabilistic damage caused to a target is replaced by a fuzzy cookie-cutter function, which takes into account many physical parameters before assessing the possibilistic damage caused to the target. This methodology of damage assessment computation of targets using fuzzy rule bases gave more realistic results when used in field training and deployment of the system.

Acknowledgments. The authors thank the Director, ISSA, for his guidance, support, encouragement and permission to present this work. We also thank Air Cmde S P Ojha, College of Air Warfare and Air Mshl. P K Mehra for the useful insights and discussions on air warfare tactics and game rules development; and the scientists of the air wargame team for their enthusiasm and support.

\section{References}

1. Banks, J. (ed.): Handbook of Simulation: Principles, Methodology, Advances, Applications, and Practice. John Wiley and Sons, New York (1998)

2. Cox, E.: The Fuzzy Systems Handbook, 2nd edn. Academic Press, New York (1999)

3. VijayRao, D.: The Design of Air Wargame System Simulation system. Technical report, Institute for Systems Studies and Analyses (2009)

4. Mendel, J.M.: Uncertain Rule-Based Fuzzy Logic Systems-Introduction and New Directions. Prentice Hall PTR, Upper Saddle River (2001) 
5. Meitzler, T.J., Singh, H., Sohn, E.: Fuzzy Logic Technique to Determine Search Time and Probability of Detection for Targets of Interest in Background Scenes, TACOM Research Development and Engineering Center, Warren, MI (2002)

6. Banks, J. (ed.): Handbook of Simulation: Principles, Methodology, Advances, Applications, and Practice. John Wiley and Sons, New York (1998)

7. Meitzler, T., Toet, A.: Advances in Target Acquisition Modeling. Opt. Eng. 40(1756) (2001) 